Title: Determination of individual chain length and chain-length distribution of polyphosphates in microalgae by ${ }^{31} \mathrm{P}$-DOSY-NMR

\title{
Journal name: Algal Research
}

Liming Wang ${ }^{1}$, Christina Kuchendorf ${ }^{2,}$ and Sabine Willbold ${ }^{1^{*}}$

1 Central Institute for Engineering, Electronics and Analytics, Analytics (ZEA-3), Forschungszentrum Jülich GmbH , 52425 Jülich, Germany,

2 Institute of Bio- and Geosciences, Plant Science (IBG-2), Forschungszentrum Jülich GmbH, 52425 Jülich, Germany,

* Corresponding author: Dr. Sabine Willbold, Forschungszentrum Jülich, Central Institute for Engineering, Electronics and Analytics (ZEA-3), D-52425 Jülich, Germany. E-mail: s.willbold@fz-juelich.de, tel: +49 2461616063, fax: +49 2461612560 


\section{Abstract}

Due to its ecological and biotechnological relevance, polyphosphate in microalgae is currently the focus of intense research. Numerous biological functions are performed by or dependent on polyphosphate, and they depend, among other factors, on its chain length. Chain length determination is important for understanding polyphosphate metabolism and for maximizing intracellular polyphosphate abundance per unit weight of biomass. ${ }^{31} \mathrm{P}$-DOSY NMR virtually separates various polyphosphate polymers in a mixture based on different translational diffusion coefficients. The diffusion coefficient of a polyphosphate molecule correlates with its molecular weight, enabling determination of individual chain lengths. Moreover, the polydispersity index can also be uniquely determined by DOSY as a measure of the overall chain-length distribution of polyphosphates. By contrast, conventional ${ }^{31} \mathrm{P}$ NMR is only able to estimate the average chain length of the entire polyphosphate pool. Therefore, DOSY provides the opportunity to deepen our insight into polyphosphate metabolism and dynamics in algal biomass.

Keywords: Polyphosphate, Algae, DOSY-NMR 


\section{Introduction}

Phosphorus $(P)$ recycling is essential for securing sustainable food and fresh water production and to respond to the ongoing depletion of natural $P$ minerals. The efficiency of $P$ usage today hardly reaches $20 \%$ with most $P$ ending up in wastewater or runoff from agriculture [1, 2]. One promising opportunity is to recover $\mathrm{P}$ via microalgae cultivation for application to crops, as microalgae are known to rapidly take up $\mathrm{P}$ from water bodies and eventually bring aquatic $\mathrm{P}$ concentration down to the environmentally safe levels in the treated wastewater [3]. As they proliferate, algal cells sequester $\mathrm{P}$ in cellular components such as phospholipids and nucleotides [4]. Under certain conditions, however, algae in $\mathrm{P}$ rich medium consumed large amounts of $\mathrm{P}$ that becomes immobilized as polyphosphates within the cells $[4,5]$. Eventually $\mathrm{P}$ can account for up to several percent of algal cell dry weight $[4,6]$, especially in the form of polyphosphate $[4$, 7]. This polyphosphate-enriched microalgae biomass can potentially be converted, e.g., to feed additives and biofertilizers [8].

Polyphosphate is a chain of inorganic phosphate containing up to several hundreds of phosphate residues linked by energy-rich phosphoanhydride bonds. In microorganisms, polyphosphate kinases and polyphosphatases are thought to be responsible for synthesis and degradation, respectively, but relatively little is known about their regulation and dynamics [9]. Biosynthesis of long- and short-chain polyphosphates tend to be mediated by distinct polyphosphatases [10]. Polyphosphate hydrolysis in soils is highly dependent on chain length of individual species [11]. Measurement of individual polyphosphate chain-length is thus an important prerequisite to generate tools and processes to, i) maximize intracellular $\mathrm{P}$ abundance per unit weight algal biomass for optimal biological $P$ removal from waste water; ii) tailor polyphosphate production of desired chain length; iii) facilitate $\mathrm{P}$ release efficiency via polyphosphate hydrolysis in soils. Conventional method such as ${ }^{31} \mathrm{P} N M R$ are only able to estimate the average chain length of the entire polyphosphate pool [5]. Here we present ${ }^{31} \mathrm{P}$ 
diffusion-ordered nuclear magnetic resonance spectroscopy (DOSY) as a practical alternative to clarify the abovementioned processes.

\section{Material and methods}

\subsection{Algae production and harvest}

Chlorella vulgaris IPPAS C1 was inoculated from laboratory flask culture (200 mL) into so-called V-bags in a greenhouse setting. We cultivated the fast growing strain in $25 \mathrm{~L} \mathrm{~V}$-shaped foil bioreactors (NovaGreen GmbH, Vechta-Langförden, Germany) as described in Schreiber et al. [12]. The culture medium was adopted from Doucha and Lívanský [13] and contained in mM: $18.32\left(\mathrm{NH}_{2}\right)_{2} \mathrm{CO}, 1.74 \mathrm{KH}_{2} \mathrm{PO}_{4}, 0.83 \mathrm{MgSO}_{4} .7 \mathrm{H}_{2} \mathrm{O}, 0.79 \mathrm{CaCl}_{2}, 0.11 \mathrm{FeNaC}_{10} \mathrm{H}_{12} \mathrm{O}_{8} \mathrm{~N}_{2}, 0.017$ $\mathrm{MnCl}_{2} .4 \mathrm{H}_{2} \mathrm{O}, 0.013 \mathrm{H}_{3} \mathrm{BO}_{3}, 0.009 \mathrm{ZnSO}_{4} .7 \mathrm{H}_{2} \mathrm{O}, 0.004 \mathrm{CuSO}_{4} .5 \mathrm{H}_{2} \mathrm{O}, 0.002 \mathrm{CoSO}_{4} .7 \mathrm{H}_{2} \mathrm{O}$, $0.0001\left(\mathrm{NH}_{4}\right)_{6} \mathrm{Mo}_{7} \mathrm{O}_{24} .4 \mathrm{H}_{2} \mathrm{O}$ and $0.0001\left(\mathrm{NH}_{4}\right) \mathrm{VO}_{3}$, made up in domestic tap water. The culture was characterized by dry weight, optical density and by orthophosphate uptake from medium, and grew non-axenic under greenhouse conditions. It was mixed by bubbling with ambient air enriched to $\mathrm{a} \mathrm{CO}_{2}$ content of $\sim 1.6 \%$. After reaching an optical density $\left(\mathrm{OD}_{735}\right)$ of 3 (approx. $1 \mathrm{~g}$ DW/I), the algae were harvested by centrifugation to $\sim 15 \% \mathrm{DW}$ content. Afterwards, aliquots were used fresh, spray-dried (SprayDrier Nebulosa GmbH, Germany), freeze-dried (Christ Alpha 2-4 LSCplus), and stored at $7^{\circ} \mathrm{C}$ for $24 \mathrm{~h}$ before further treatment.

\subsection{Alkaline extraction}

Spray-dried algae (Chlorella vulgaris) were extracted following a common procedure for soil samples [14]. Briefly, $100 \mathrm{mg}$ of algae were dispersed in $2 \mathrm{~mL}$ of a mixture of $0.25 \mathrm{M} \mathrm{NaOH}$ and $0.05 \mathrm{M}$ EDTA, and shaken for 16 hours. After centrifugation at $10.000 \mathrm{~g}$ for $30 \mathrm{~min}$, the supernatant was decanted and lyophilized at $-80^{\circ} \mathrm{C}$. The freeze-dried powder was resuspended in $500 \mu \mathrm{L}$ of $\mathrm{NaOD}$ in $\mathrm{D}_{2} \mathrm{O}(\mathrm{pH}$ 13) for NMR measurement, with $100 \mu \mathrm{L}$ methylenediphosphonic acid solution (MDPA, $0.83 \mathrm{mg} \cdot \mathrm{mL}^{-1}$ ) added as an internal reference standard. $\mathrm{P}$ recovery after 
extraction was $67.5 \%$ relative to total $\mathrm{P}$ measured by inductively coupled plasma optical emission spectrometry (ICP-OES).

\subsection{NMR parameters}

NMR acquisition was performed on a Bruker $600 \mathrm{MHz}$ spectrometer and on a Varian $600 \mathrm{MHz}$ spectrometer equipped with a $5 \mathrm{~mm}$ cryoprobe tuned to ${ }^{31} \mathrm{P}$ frequency. A $1 \mathrm{D}$ spectrum was acquired with following parameters: $90^{\circ}$ pulse length, $1 \mathrm{~s}$ acquisition time, $15 \mathrm{~s}$ relaxation delay, 298.0 K, 616 transients, inverse-gated proton decoupling. DOSY Parameters were: $3.5 \mathrm{~ms}$ diffusion gradient length $(\delta), 100$ ms diffusion delay $(\Delta), 15$ gradient increments with gradient strength $(g)$ from 1.3 to 32.5 G.cm- ${ }^{1}$. The combination of $\delta$ and $\Delta$ was optimized to provide at least $85 \%$ signal attenuation at the strongest gradient field [15]. The figures and data presented here were derived from one single DOSY measurement, which was based on preliminary tests. Due to the expense and time involved, NMR measurement of replicates is regularly not performed [16]. The error for NMR analysis of $\mathrm{NaOH}$-EDTA extracts from preliminary tests and reported data was between 5\% and 10\% [17]. 1D NMR and DOSY results were processed by MestRenova software (version 8.1.2) and VnmrJ software (version 4.2, revision A), respectively. Line broadening was set as $2 \mathrm{~Hz}$. In order to obtain a good quality NMR dataset, i.e., cleaner baseline, less gradient-dependent phase distortion, DOSY was carried out with a BPPSTE [18] (bipolar pulse pair stimulated echo) pulse sequence to cancel gradient perturbation [19].

The second domain of DOSY was constructed with diffusion value (D) of individual signal. D is inversely proportional to molecular weight (MW) as shown in Equation 1:

$D \propto M W^{-1 / 3}$

(1) [20]

Moreover, polydispersity index (PDI) was determined by DOSY as following Equation 2: 
$P D I=\left(\frac{<D_{w}>}{<D_{n}>}\right)^{-d_{f}}$

(2) [21]

where $\left\langle D_{w}\right\rangle$ and $\left\langle D_{n}>\right.$ were the mean $\mathrm{D}$ measured for the whole polyphosphate and the terminal phosphate units, respectively. $d_{f}$ is a constant. PDI is greater than or equal to 1,approaching to 1 as the polymer chains approach uniformity, and describes the heterogeneity of a given polymer mixture.

\section{Results and discussion}

As shown in the 1D spectrum (Figure 1), the diverse $\mathrm{P}$ pool of algae was composed of phosphonates, orthophosphate, monoesters, diesters, pyrophosphate and polyphosphates. The signals of MDPA, orthophosphate, pyrophosphate, and terminal $\mathrm{P}$ of tripolyphosphate were readily recognizable. The DOSY spectrum in Figure 2 virtually separated signals based on the molecular sizes of corresponding solutes. Along the vertical axis of the DOSY spectrum, the diffusion value was represented as the center of each cross peak, with its standard deviation plotted as peak width [22]. Usually, weak signals feature a larger peak width because they are susceptible to statistical errors due to interference of noise and distortion. For example, the signal width of MDPA on DOSY is relatively larger than that of orthophosphate, despite both being singlets in the 1D spectrum. The two terminal $\mathrm{P}$ nuclei of tripolyphosphate contributed to a DOSY doublet wider than both MDPA and orthophosphate. Its internal P, by contrast, resonated as a triplet in the 1D spectrum. The signal intensity, however, is too low, and the standard deviation of the diffusion value is consequently large enough (relative standard deviation $>10 \%$ ) to be rejected by VnmrJ software during the diffusion value calculation. Therefore, the internal $\mathrm{P}$ of tripolyphosphate did not provide any signal on DOSY spectrum.

To estimate the MW of unknown polyphosphate signals based on their diffusion values, a common practice is to build a calibration curve by correlating the logarithm of the diffusion value of identified signals with their theoretical MW. Here the readily identified signals of MDPA, 
orthophosphate, pyrophosphate, and tripolyphosphate were selected to construct the regression line (Figure 3). Notably, the difference between predicted and theoretical MW was up to $7.3 \%$ (Table 1), well below the $10 \%$ limit of accuracy for DOSY experiment [23], suggesting the reliability of data fitting. Based on the equation shown in Figure 3, the MW of polyphosphate can be mathematically derived from the corresponding diffusion value as summarized in Table 1. The chemical formula of polyphosphate can be simplified as $\left(\mathrm{NaO}_{3} \mathrm{P}\right) \mathrm{n}$, with the number of monomers calculated by the dividing estimated $\mathrm{MW}$ of each signal by $\mathrm{MW}$ of $\mathrm{NaO}_{3} \mathrm{P}(101.96$ Da). The strong internal $\mathrm{P}$ signal at $21.6 \mathrm{ppm}$ was likely composed of polydisperse polyphosphates rather than a single polyphosphate species with 124 monomers as calculated. Presumably, for long-chain polyphosphates the chemical environments of the internal $\mathrm{P}$ monomers is too similar to be resolved by NMR. As DOSY principally delivers one D value, i.e., one chain length, per NMR signal, the signal at $21.6 \mathrm{ppm}$ derived from more than one substance, represents a weighted value of all polyphosphates contributing to the signal [22]. However, DOSY was able to accurately estimate the PDI as a measure of the overall chainlength distribution of polyphosphates. Here for the first time, the PDI of algal polyphosphate was determined by DOSY to be 1.95, suggesting considerable polyphosphate heterogeneity. Polyphosphates were mostly stable under alkaline conditions but were still subject to slow hydrolysis during sample preparation and measurement [24]. This should be taken into account when interpreting data, as the structural information, reflected by the NMR spectrum, was thus artificially altered to certain extent. We estimated that $12.7 \%$ of condensed P (unpublished data) was degraded into tripolyphosphate, pyrophosphate, and orthophosphate during extraction.

DOSY is gaining popularity for P studies, for instance in soil samples [25]. In contrast with soils typically containing $0.1-3 \mathrm{mg} \mathrm{g}^{-1}$ total $\mathrm{P}$ [26], algal biomass usually contains larger amounts of $\mathrm{P}\left(8.32 \mathrm{mg} \mathrm{g}^{-1}\right.$ here) but fewer paramagnetic ions such as Fe $\left(0.50 \mathrm{mg} \mathrm{g}^{-1}\right)$ and $\mathrm{Mn}\left(0.04 \mathrm{mg} \mathrm{g}^{-1}\right)$. In addition, a sample suspension of algae is much less viscous than that of soil samples, 
because the latter is rich in clay minerals. Therefore, the NMR spectral quality of algae characterized by high S/N ratio and resolution is favorable for DOSY analysis.

\section{Conclusion}

DOSY is expected to be a promising technique for studies of polyphosphates in algae. Here it was for the first time introduced as a practical approach for the estimation of individual chainlength of well-resolved signals and the overall heterogeneity of polyphosphates.

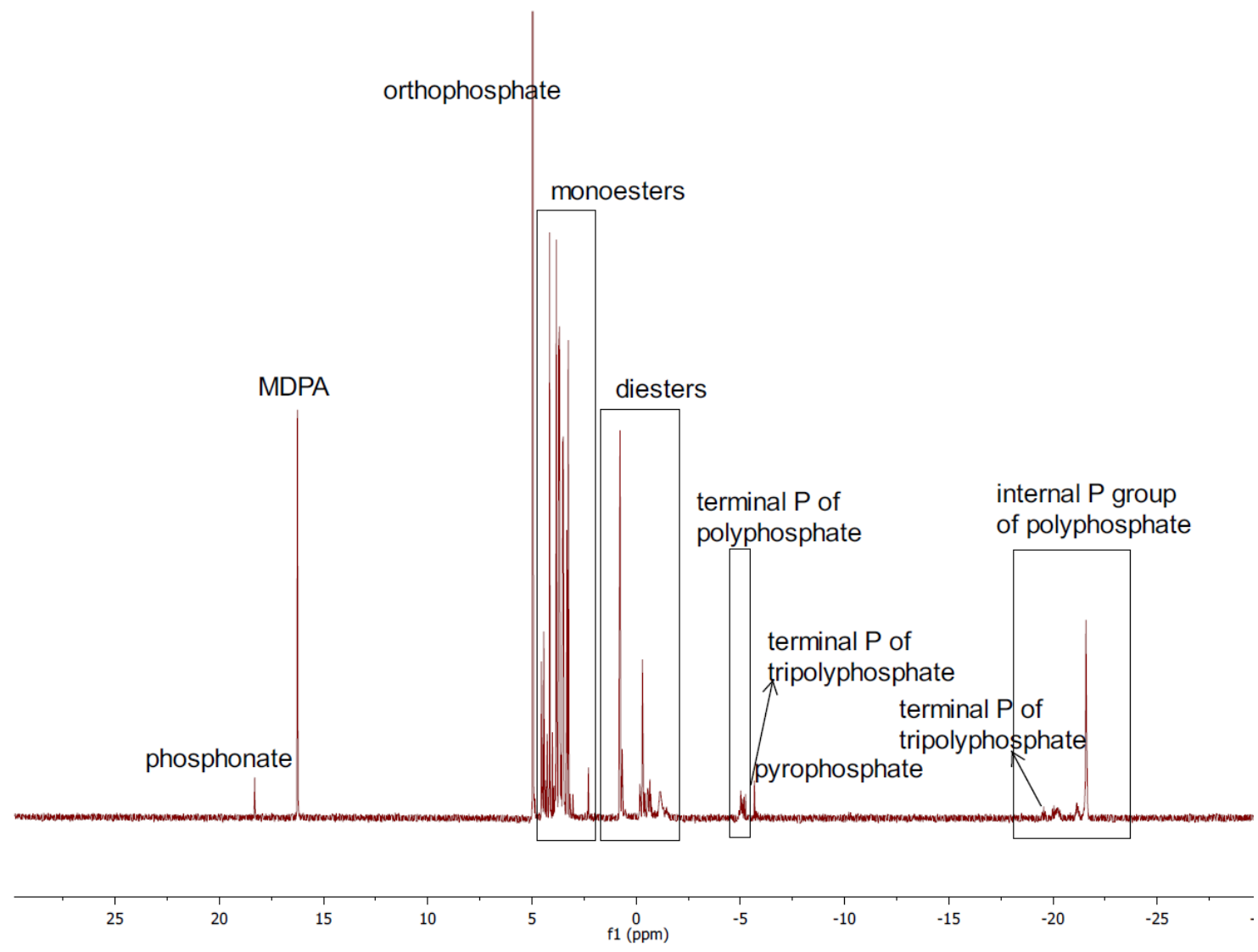

Figure 1. 1D ${ }^{31} \mathrm{P}-\mathrm{NMR}$ spectrum of alkaline extract of green algae (Chlorella vulgaris). 


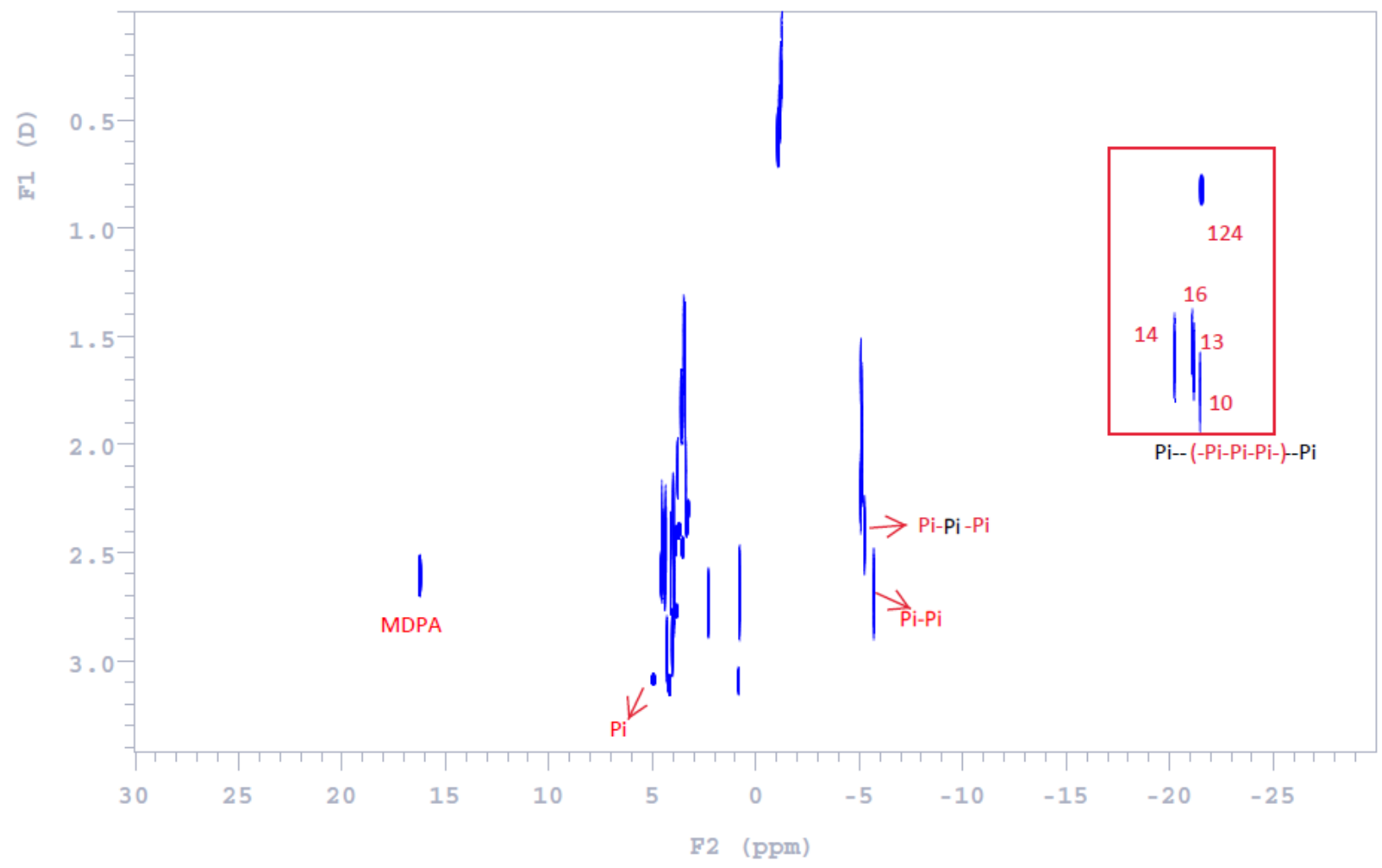

Figure 2. ${ }^{31} \mathrm{P}$-DOSY-NMR spectrum of Algae (Chlorella vulgaris) alkaline extract. Numbers in red represented the number of monomers.

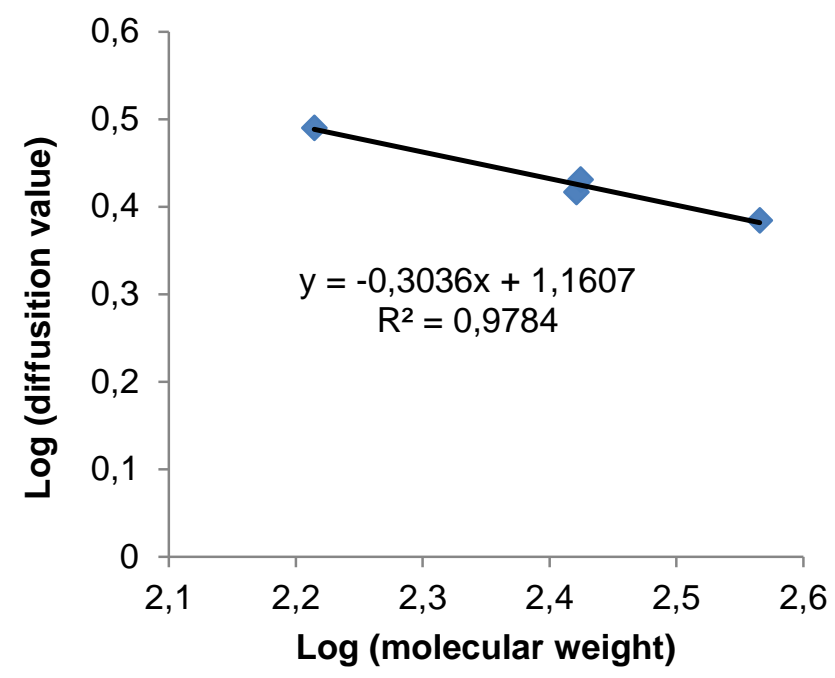


Figure 3 Linear regression between logarithm of diffusion value and MW of 4 identified components, including MDPA, orthophosphate, pyrophosphate, and tripolyphosphate in algae (Chlorella vulgaris).

Table 1 D-MW correlation analysis of DOSY data for algae sample

\begin{tabular}{|c|c|c|c|c|c|}
\hline Compound ID & $\begin{array}{l}\text { Diffusion } \\
\left(10^{-10} \mathrm{~m}^{2} \mathrm{~s}^{-1}\right)\end{array}$ & $\begin{array}{l}\text { True MW } \\
\text { (Da) }\end{array}$ & $\begin{array}{l}\text { Estimated } \\
\text { MW (Da) }\end{array}$ & $\begin{array}{l}\% \\
\text { Difference }\end{array}$ & $\begin{array}{l}\text { Number of } \\
\text { monomers }\end{array}$ \\
\hline MDPA & 2.6074 & 263.9 & 283.3 & 7.34 & \\
\hline Orthophosphate & 3.0891 & 163.9 & 162.1 & 1.14 & 1 \\
\hline Pyrophosphate & 2.6938 & 265.9 & 254.4 & 4.31 & 2 \\
\hline Tripolyphosphate & 2.4199 & 367.9 & 362.2 & 1.54 & 3 \\
\hline \multirow[t]{4}{*}{ Terminal P } & 2.2215 & & 480.1 & & 5 \\
\hline & 1.6755 & & 1215.7 & & 12 \\
\hline & 1.8398 & & 893.3 & & 9 \\
\hline & 2.0515 & & 624.0 & & 6 \\
\hline Internal $P$ of & 1.5966 & & 1425.1 & & 14 \\
\hline \multirow[t]{4}{*}{ Polyphosphate } & 1.5291 & & 1643.0 & & 16 \\
\hline & 1.6162 & & 1368.9 & & 13 \\
\hline & 1.7576 & & 1038.5 & & 10 \\
\hline & 0.8233 & & 12625.8 & & 124 \\
\hline
\end{tabular}

\section{Conflict of interest:}

The authors declare that they have no conflicts of interest with the contents of this article.

\section{Statement of informed consent, human or animal rights}


Not applicable.

\section{Author contributions}

SW initiated and coordinated the study. CK carried out algae production and harvest. LW conducted all other experiments and drafted the manuscript. All authors agree to authorship and approve final manuscript for submission.

\section{Acknowledgements}

Funding information: This research was financially supported by the BioSC seed fund project QuantiP, funded by the Ministry of Innovation, Science and Research of the German State of North Rhine-Westphalia and the China Scholarship Council; and Algnutrient-UrBioSol (FKZ 031B0453A) of the Federal Ministry of Education and Research (BMBF).

\section{References}

[1] J.J. Elser, M.E. Bracken, E.E. Cleland, D.S. Gruner, W.S. Harpole, H. Hillebrand, J.T. Ngai, E.W. Seabloom, J.B. Shurin, J.E. Smith, Global analysis of nitrogen and phosphorus limitation of primary producers in freshwater, marine and terrestrial ecosystems, Ecology letters, 10 (2007) 1135-1142. [2] D. Cordell, J.-O. Drangert, S. White, The story of phosphorus: Global food security and food for thought, Global Environmental Change, 19 (2009) 292-305.

[3] N. Boelee, H. Temmink, M. Janssen, C. Buisman, R. Wijffels, Nitrogen and phosphorus removal from municipal wastewater effluent using microalgal biofilms, Water research, 45 (2011) 5925-5933.

[4] N. Powell, A. Shilton, Y. Chisti, S. Pratt, Towards a luxury uptake process via microalgae-defining the polyphosphate dynamics, Water research, 43 (2009) 4207-4213.

[5] U. Pilatus, A. Mayer, A. Hildebrandt, Nuclear polyphosphate as a possible source of energy during the sporulation of Physarum polycephalum, Archives of biochemistry and biophysics, 275 (1989) 215-223.

[6] H.G. Wood, J.E. Clark, Biological aspects of inorganic polyphosphates, Annual review of biochemistry, 57 (1988) 235-260.

[7] A.N. Shilton, N. Powell, B. Guieysse, Plant based phosphorus recovery from wastewater via algae and macrophytes, Current opinion in biotechnology, 23 (2012) 884-889.

[8] W. Mulbry, E.K. Westhead, C. Pizarro, L. Sikora, Recycling of manure nutrients: use of algal biomass from dairy manure treatment as a slow release fertilizer, Bioresource technology, 96 (2005) 451-458. [9] M. Akiyama, E. Crooke, A. Kornberg, An exopolyphosphatase of Escherichia coli. The enzyme and its ppx gene in a polyphosphate operon, Journal of Biological Chemistry, 268 (1993) 633-639.

[10] M.J. Seufferheld, M.J. Curzi, Recent Discoveries on the Roles of Polyphosphates in Plants, Plant Molecular Biology Reporter, 28 (2010) 549-559.

[11] R.P. DICK, M.A. TABATABAI, HYDROLYSIS OF POLYPHOSPHATES IN SOILS, Soil Science, 142 (1986) 132-140. 
[12] C. Schreiber, D. Behrendt, G. Huber, C. Pfaff, J. Widzgowski, B. Ackermann, A. Müller, V. Zachleder, Š. Moudříková, P. Mojzeš, U. Schurr, J. Grobbelaar, L. Nedbal, Growth of algal biomass in laboratory and in large-scale algal photobioreactors in the temperate climate of western Germany, Bioresource Technology, 234 (2017) 140-149.

[13] J. Doucha, K. Lívanský, Productivity, $\mathrm{CO} 2 / \mathrm{O} 2$ exchange and hydraulics in outdoor open high density microalgal (Chlorella sp.) photobioreactors operated in a Middle and Southern European climate, J Appl Phycol, 18 (2006) 811-826.

[14] B.J. Cade-Menun, C.M. Preston, A comparison of soil extraction procedures for 31P NMR spectroscopy, Soil Science, 166 (1996).

[15] K.E. Price, L.H. Lucas, C.K. Larive, Analytical applications of NMR diffusion measurements, Analytical and bioanalytical chemistry, 378 (2004) 1405-1407.

[16] B.L. Turner, L.M. Condron, S.J. Richardson, D.A. Peltzer, V.J. Allison, Soil organic phosphorus transformations during pedogenesis, Ecosystems, 10 (2007) 1166-1181.

[17] B.J. Cade-Menun, C.R. Benitez-Nelson, P. Pellechia, A. Paytan, Refining 31P nuclear magnetic resonance spectroscopy for marine particulate samples: Storage conditions and extraction recovery, Marine Chemistry, 97 (2005) 293-306.

[18] G. Wider, V. Dotsch, K. Wuthrich, Self-compensating pulsed magnetic-field gradients for short recovery times, Journal of Magnetic Resonance, Series A, 108 (1994) 255-258.

[19] M.D. Pelta, H. Barjat, G.A. Morris, A.L. Davis, S.J. Hammond, Pulse sequences for high - resolution diffusion - ordered spectroscopy (HR - DOSY), Magnetic resonance in chemistry, 36 (1998) 706-714.

[20] G. Zheng, W.S. Price, Environmental NMR: Diffusion Ordered Spectroscopy Methods, eMagRes, 2 (2014) 561-574.

[21] J. Viéville, M. Tanty, M.-A. Delsuc, Polydispersity index of polymers revealed by DOSY NMR, Journal of Magnetic Resonance, 212 (2011) 169-173.

[22] G.A. Morris, Diffusion - Ordered Spectroscopy, eMagRes, (2009).

[23] W. Li, G. Kagan, H. Yang, C. Cai, R. Hopson, D.A. Sweigart, P.G. Williard, Physically Separated References for Diffusion Coefficient-Formula Weight (D-FW) Analysis of Diffusion-Ordered NMR Spectroscopy (DOSY) in Water, Organic letters, 12 (2010) 2698-2701.

[24] J.P. Crowther, A. Westman, The Hydrolysis of the Condensed Phosphates: I. Sodium Pyrophosphate and Sodium Triphosphate, Canadian Journal of Chemistry, 32 (1954) 42-48.

[25] L. Wang, W. Amelung, S. Willbold, Diffusion-ordered nuclear magnetic resonance spectroscopy (DOSY-NMR): a novel tool for identification of phosphorus compounds in soil extracts, Environmental Science \& Technology, (2017).

[26] L.M. Condron, B.L. Turner, B.J. Cade-Menun, Chemistry and dynamics of soil organic phosphorus, in: J.T. Sims, and Sharpley, A.N. (Ed.) Phosphorus: Agriculture and the environment, Agron. Monogr. 46. ASA, CSSA, and SSSA2005, pp. 87-121. 